\title{
A facade-integrated Multi-Source Heat Pump in combination with a Ventilation System for Heating and Cooling
}

\author{
Dietmar Siegele ${ }^{1}$, Fabian Ochs ${ }^{1}$ \\ ${ }^{1}$ University of Innsbruck, Unit for Energy Efficient Building, 6020 Innsbruck, Austria
}

\begin{abstract}
In refurbishment of multi-family houses heat pumps for heating purpose are rarely used. If in a deep renovation a ventilation unit is mounted, the ducts could be used also for heating.

For this reason, a ventilation unit combined with a multisource heat pump (exhaust and ambient air) was developed, built, tested and simulated. It is suitable for heating and cooling apartments and small buildings with a heating capacity of up to $2.5 \mathrm{~kW}$. With the presented solution often-obtained problems with air heating systems, such as dry air due to high volume flows or overheating of the supply air rooms can be avoided. A simulation study with a calibrated heat pump model was done to proof the concept.
\end{abstract}

\section{Motivation and Concept}

Energy-efficient buildings are often equipped with controlled ventilation system with supply and exhaust air. The existing air ducts can also be used for heating and cooling the building (Ochs et al, 2017). This solution is an attractive alternative to split and multi-split units. It is cost-effective and can be installed visually attractive. For example, it can be combined with façade-integrated modules and innovative air duct systems.

That this kind of concepts with small heating capacities of around $1 \mathrm{~kW}$ are working was already shown by (Dermentzis et al, 2017). From a more theoretical point of view such concepts were presented e.g. also by (Mortada et al, 2010).

But the limited heating capacity requires a high efficient refurbishment. This cannot always be realized, in most cases due to economic and social reasons. For this reason, a ventilation unit combined with a multi-source heat pump (exhaust and ambient air) was developed and built (Ochs et al, 2018). It is suitable for heating and cooling apartments and small buildings with a heating capacity of up to $2.5 \mathrm{~kW}$.

Due to lack of space in the façade for the whole device it was split into two parts: an outdoor and an indoor unit (compare Figure 1).

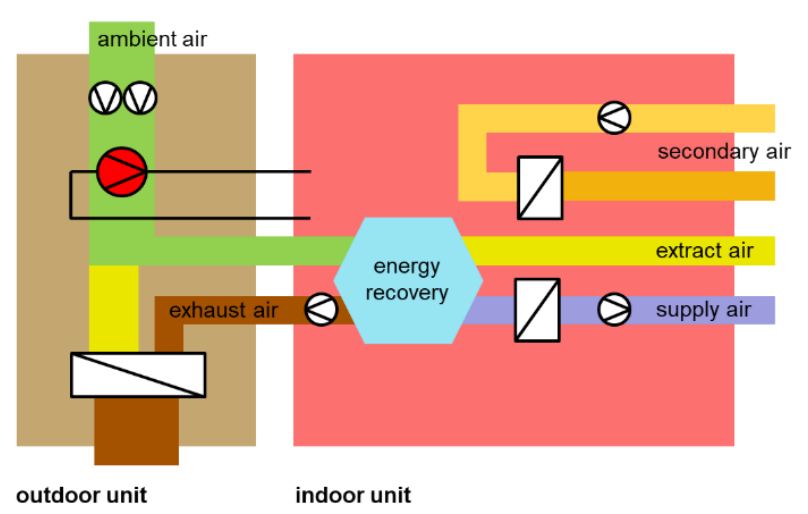

Figure 1: Components and air flows of the device with the outdoor and the indoor unit.

Figure 2 shows the scheme of the indoor unit, which can be e.g. mounted on the ceiling of the kitchen or bathroom. The device uses an energy recovery exchanger to reduce the ventilation losses. The volume flow of the supply and extract air can be in the range of 80 to $120 \mathrm{~m}^{3} / \mathrm{h}$. This amount of air is too less to provide the whole heating capacity of the heat pump via fresh air. The maximum possible heat capacity is around $10 \mathrm{~W} / \mathrm{m}^{2}$. For this reason additional secondary air is used (volume flow of 0 to $135 \mathrm{~m}^{3} / \mathrm{h}$ ) and heated up with a second condenser. The deicing of the heat pump is realized with a hot-gas bypass.

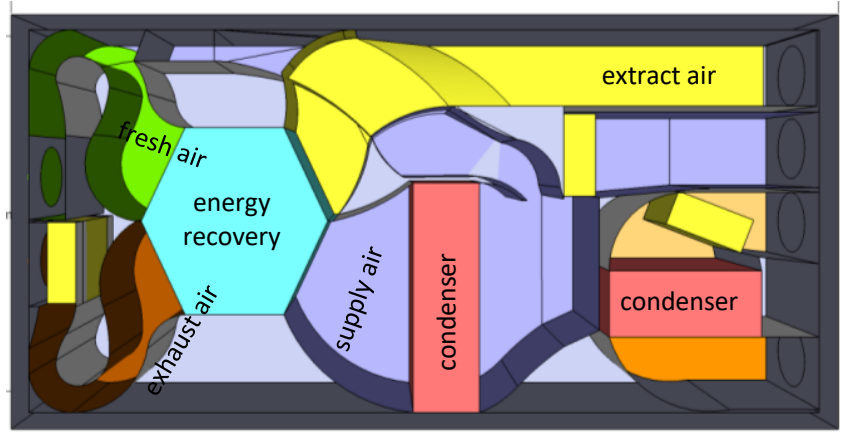

Figure 2: Scheme of the indoor unit.

Figure 3 (a) shows the outdoor unit, which is façadeintegrated. The outdoor unit contains the evaporator, the compressor and the inverter for the heat pump. The evaporator uses the exhaust air of the indoor unit and additional ambient air (up to $200 \mathrm{~m}^{3} / \mathrm{h}$ ). 


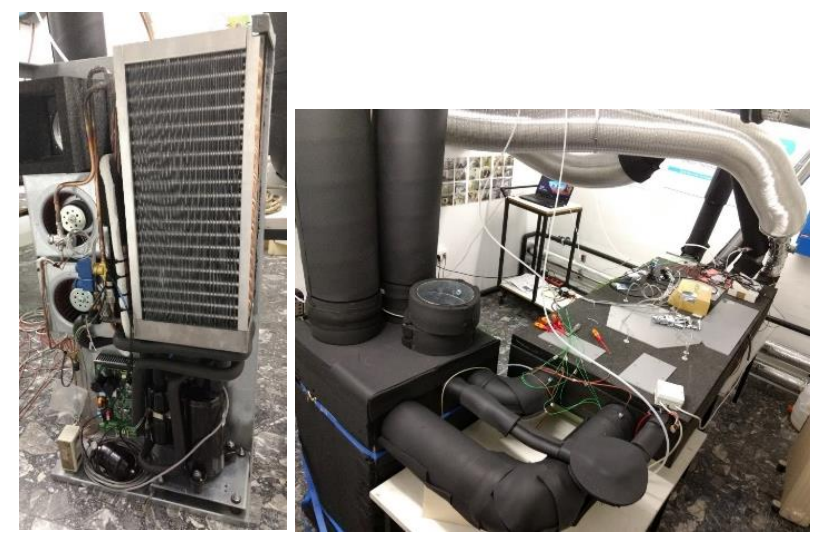

Figure 3: (a) Façade-integrated outdoor unit with evaporator and compressor, (b) Whole heat pump in the test facility of the University of Innsbruck.

\section{Method}

\section{Measurements}

The described multi-source heat pump was built and tested in the laboratories of the University of Innsbruck. In the compact unit test facility, air to air heat pumps and ventilation units can be tested. Up to eight different air flows can be measured at the same time regarding temperature, humidity and volume flow. Two climate chambers can be conditioned and can be used for emulating the boundary conditions.

Steady-state measurement for different system states and different boundary conditions were done. Moreover, the transient behaviour regarding time constants of the heat pump and icing-behaviour were obtained.

Figure 3 (b) shows the heat pump in the laboratory connected to the measurement equipment.

All the presented results belonging thermal power and energy have an accuracy of around $5 \%$. The electrical power and energy have an accuracy of $0.5 \%$.

\section{Simulations}

MATLAB Simulink with the uibkCARNOT Toolbox (Siegele, Leonardi 2019) is used as a simulation platform. For all simulations a 2-star-node model is used. The structure is simulated with a hygrothermal model. Air exchange between two adjacent zones through open doors is modelled based on an empirical model used in the uibkCARNOT Toolbox.

The building under consideration is a typical multi-storey residential building (Figure 4 and Figure 5). It consists of five storeys and two symmetrical flats for each storey. The staircase and the basement are not heated and a monthly average ground temperature based on calculations according to the ISO 13370:2017 is considered. The reference flat (with an area of $70.9 \mathrm{~m}^{2}$ ) considered here is the flat of the first floor oriented to north-east. The flat consists of six thermal zones (one for each room), while the other flats (above and adjacent, below) and the staircase are each as one zone calculated.

It is assumed that the doors of the kitchen and living room are always opened, while the other doors (i.e. bathroom, child room and sleeping room) are always closed.

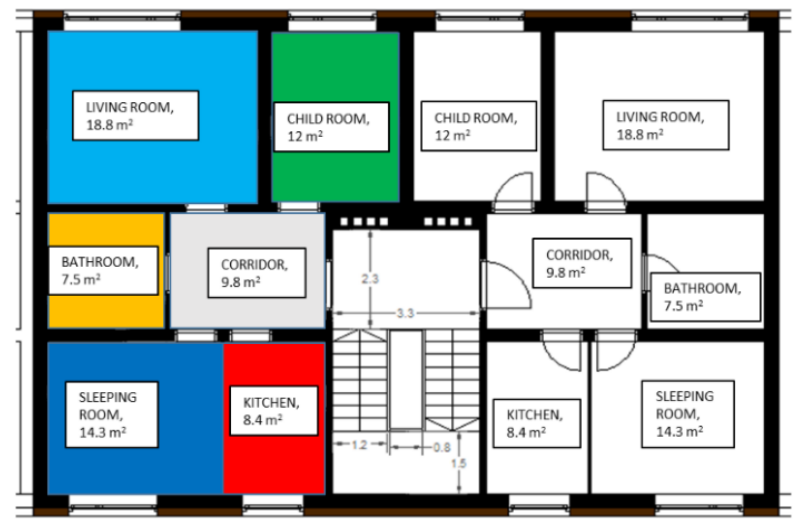

Figure 4: Plan of the multi-storey building (10 flats, two symmetrical flats for each store), in colours: the flat considered for the detailed considerations.

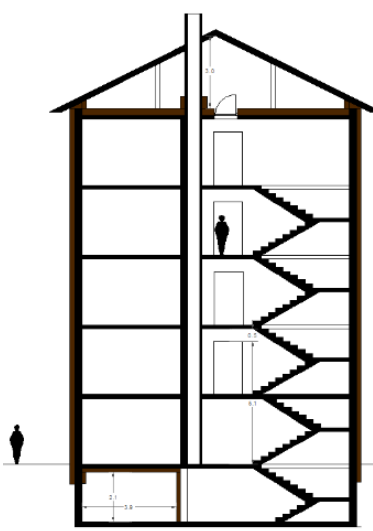

Figure 5: Section of the building.

A mechanical ventilation unit with energy recovery (ERV) supplies fresh air to the parents room, child room and living room $\left(40 / 20 / 40 \mathrm{~m}^{3} / \mathrm{h}\right.$ in standard conditions) and extracts air from the kitchen and bathroom $\left(60 / 40 \mathrm{~m}^{3} / \mathrm{h}\right.$ in standard conditions $)$.

An ERV model was implemented, using an expanded etaNTU analytical approach considering the relative humidity of the extract air (compare (Siegele, 2018) and (Ochs, 2017)). The sensible and latent effectiveness were determined from the measurements.

The heat pump simulation base on look-up tables determined from the measurements. Transfer functions were taken into account to consider the transient behaviour of the heat pump (switching on or off the heat pump and de-icing). The de-icing behaviour was simulated with a timer. A running time of 1.5 hours and a de-icing time of 10 minutes are considered.

The control is based on a cascade of two PI controllers. The room temperature is in this study always measured in the hallway. The first PI controller produces the set point for the supply air temperature. The second one controls the speed of the compressor to reach the necessary supply air temperature.

To avoid thermal discomfort additional room-wise electrical heaters are considered in different operation modes. For comfort reason an electrical radiator in the bathroom is always necessary. For the sake of simplicity 
this it uses always the same set point of $21.0^{\circ} \mathrm{C}$. In reality the energy consumption can be significantly reduced by an "on-demand" controller.

An air change rate of $0.07 \mathrm{~h}^{-1}$ (constant throughout the year) due to infiltration is assumed.

An active cooling was in the presented simulations not considered. The heat pump can provide also cooling. These results will be presented in further publications.

External movable shading blinds limit the solar gains during the summer and passive cooling of the flat is ensured by activation of night cooling ventilation and opening of the windows (see (Ochs et al, 2018) for detailed information about the control strategies implemented).

The reference flat is occupied by three persons (approx. $24 \mathrm{~m}^{2} /$ person). It is assumed that the daily schedule of the occupation profile is valid also during the weekend. Additional information about the building model (e.g. internal gains, control strategies, wall constructions, etc.) can be found in (Ochs et al, 2018).

Tree different climates were considered: Innsbruck (AT), Warth (AT) and Lyon (FR).

\section{Key Performance Indicators}

To describe the efficiency of the heat pump the following KPIs were defined.

To describe the coefficient of performance (COP) the equation (1) is used.

$$
C O P_{H P}=\frac{\dot{Q}_{\text {sup }}+\dot{Q}_{\text {sec }}}{P_{\text {el, comp }}+P_{\text {ven }, \text { sec }}+P_{\text {ven }, a m b}+P_{\text {el,valve }}}
$$

$\dot{\mathrm{Q}}_{\text {sup }}$ is the heating capacity of the supply air. $\dot{Q}_{\text {sec }}$ is the heating capacity of the secondary air. $P_{e l, c o m p}$ is the electrical consumption of the compressor (including inverter losses). $P_{\text {ven,sec }}$ the electrical consumption of the ventilator for the secondary air. $P_{v e n, a m b}$ the electrical consumption of the ventilator for the additional ambient air. $P_{\text {vent,valve }}$ is the electrical consumption for the magnetic valves in the refrigerant cycle. The controller is currently neglected. All the values are obtained from the measurements.

For the seasonal performance the seasonal performance factor (SPF) is used according to equation (2).

$$
\begin{gathered}
S P F_{H P}=\frac{Q_{s u p}+Q_{s e c}}{E_{e l, H P}} \\
E_{e l, H P}=P_{e l, \text { comp }}+E_{\text {ven }, \text { sec }}+E_{\text {ven,amb }}+E_{\text {el,valve }}+E_{\text {el,deicng }}
\end{gathered}
$$

In constrast to equation (1) energies in spite of powers are used. Additionally the energy for the de-icing $E_{\text {el,deicing }}$ is considered, which is realized by a hot-gas bypass in the refrigerant cycle.

For the system performance of the heat pump additional room-wise electrical heaters have to be considered according to equation (4).

$$
S P F_{\text {sys }}=\frac{Q_{\text {sup }}+Q_{\text {sec }}}{E_{\text {el,HP }}+E_{\text {el,heaters }}}
$$

$E_{\text {el,heaters }}$ is the energy consumption of the room-wise electrical heaters.

In this publication the ventilation system is not further discussed or rated and not considered in the system performance. In (Calabrese et al, 2018) the ventilation system in combination with the heat pump was already evaluated.

\section{Measurement Results and Discussion}

The presented concept was built in in two different configurations for a heating capacity of $2500 \mathrm{~W}$ and also for $1400 \mathrm{~W}$. Only the results of the former are going to be presented here.

The ventilation system in combination with the heat pump can be used in different operating modes:

- $\quad$ only ventilation (compare (Siegele 2018));

- heating via the supply air (80 and $100 \mathrm{~m}^{3} / \mathrm{h}$ ), secondary air off;

- heating via the supply air $\left(80\right.$ and $\left.100 \mathrm{~m}^{3} / \mathrm{h}\right)$ and additional secondary air (65 to $\left.135 \mathrm{~m}^{3} / \mathrm{h}\right)$;

- heating via secondary air (this mode is not investigated here).

Moreover the heat pump has additional operating modes by using the different air flows (multisource heat pump):

- exhaust air,

- exhaust air and ambient air,

- ambient air.

This variety of operation modes allows to optimize the controller which is later described.

The following figures show the steady-state measurement results of the device for different operating modes. The scaling of the $y$-axis is always the same, which allows a direct comparison of different operation modes. The given air flow rates are always calculated for norm conditions $\left(20^{\circ} \mathrm{C}, 50 \%\right.$ r.H. $)$. In fact the device uses mass flow rates to keep the balances and e.g. heating up the supply air effects a higher air volume flow. Following results are presented:

- Supply air with exhaust air heat pump

- Supply and secondary air with exhaust air heat pump

- Supply and secondary air with exhaust and ambient air heat pump

Figure 6 show the heating capacity for the "pure" supply air heating system with an air flow rate of $100 \mathrm{~m}^{3} / \mathrm{h}$. The different isolines represent the speed of the compressor in rounds per minute (rpm). This operating mode uses the exhaust air as source. To prevent overheating of the compressor and inverter an additional minimal air flow rate (ambient air) of approx. $30 \mathrm{~m}^{3} / \mathrm{h}$ used.

With the lowest speed a heating capacity between $500 \mathrm{~W}$ and $650 \mathrm{~W}$ can be obtained. The maximum heating capacity is limited because the air temperature should not exceed $55^{\circ} \mathrm{C}$. This is necessary to avoid carbonization of the dust and due to this bad smell. With the limitation to $100 \mathrm{~m}^{3} / \mathrm{h}$ (norm air flow rate) for the supply air a maximum heating capacity of $1250 \mathrm{~W}$ can be reached. 


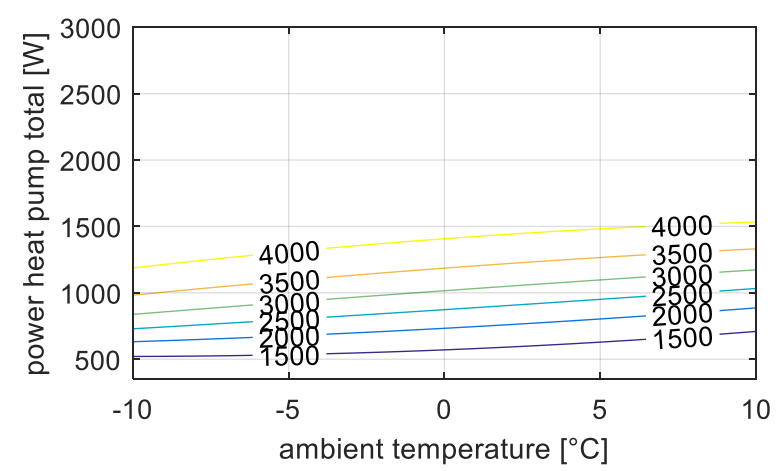

Figure 6: Heating capacity depending on speed of the compressor for supply air $100 \mathrm{~m}^{3} / \mathrm{h}$ and exhaust air $100 \mathrm{~m}^{3} / \mathrm{h}$

Figure 7 shows the coefficient of performance (COP) for this case. Values between 1.4 and 3.0 can be obtained.

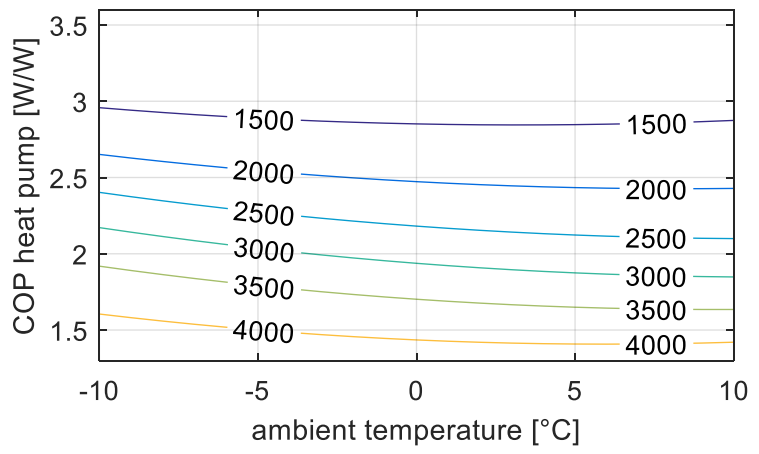

Figure 7: COP depending on speed of the compressor for supply air $100 \mathrm{~m}^{3} / \mathrm{h}$ and exhaust air $100 \mathrm{~m}^{3} / \mathrm{h}$.

Figure 8 shows the heating capacity in case of an additional secondary air flow rate with $100 \mathrm{~m}^{3} / \mathrm{h}$. The heat pump still uses only the exhaust air as source. Due to the higher volume air flow rates the maximum heating capacity (supply air and secondary air) can be increased to 1500 to $2100 \mathrm{~W}$. In this case the exhaust air flow rate is the limiting factor.

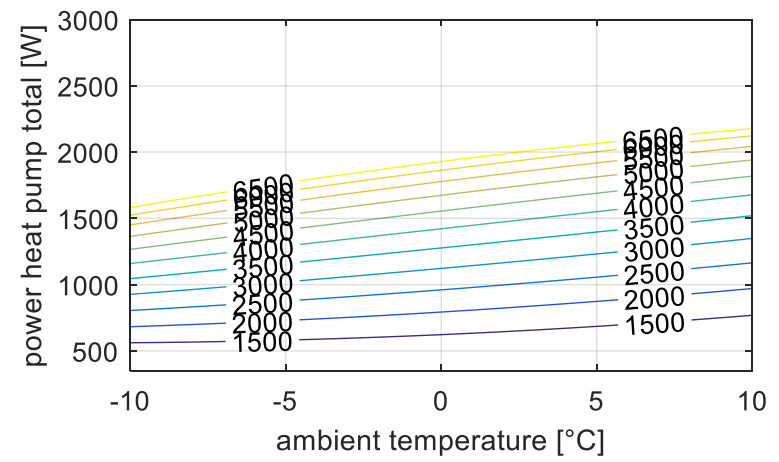

Figure 8: Heating capacity depending on speed of the compressor for supply air $100 \mathrm{~m}^{3} / \mathrm{h}$, secondary air $100 \mathrm{~m}^{3} / \mathrm{h}$ and exhaust air $100 \mathrm{~m}^{3} / \mathrm{h}$.

Figure 9 shows the COP for the corresponding case. An increase over the whole compressor speed range can be obtained.

Figure 10 shows the case with an additional secondary air flow rate of $100 \mathrm{~m}^{3} / \mathrm{h}$ and an additional ambient air flow rate of $200 \mathrm{~m}^{3} / \mathrm{h}$ for the heat pump. A further increase of the heating capacity can be obtained and a heating capacity of 2000 to more than $3000 \mathrm{~W}$ can be expected.

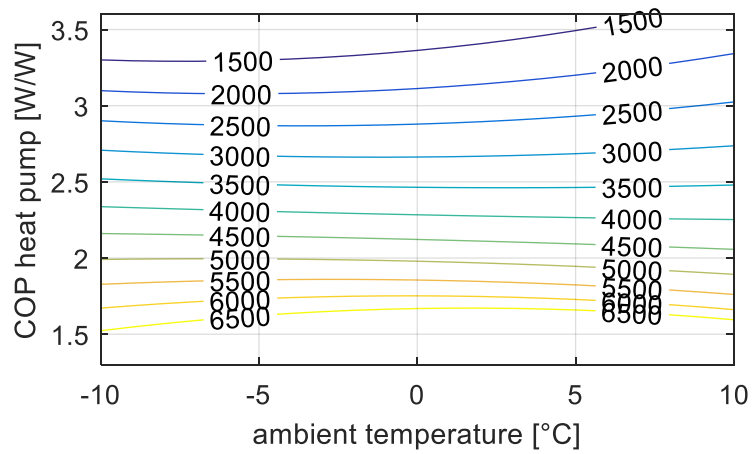

Figure 9: COP depending on speed of the compressor for supply air $100 \mathrm{~m}^{3} / \mathrm{h}$, secondary air $100 \mathrm{~m}^{3} / \mathrm{h}$ and exhaust air $100 \mathrm{~m}^{3} / \mathrm{h}$.

Figure 11 shows the COP for this operating mode. For higher compressors speeds it is comparable with Figure 9. For lower compressor speeds the COP decreases because the electrical power consumption of the ambient ventilator has a high influence on the overall performance.

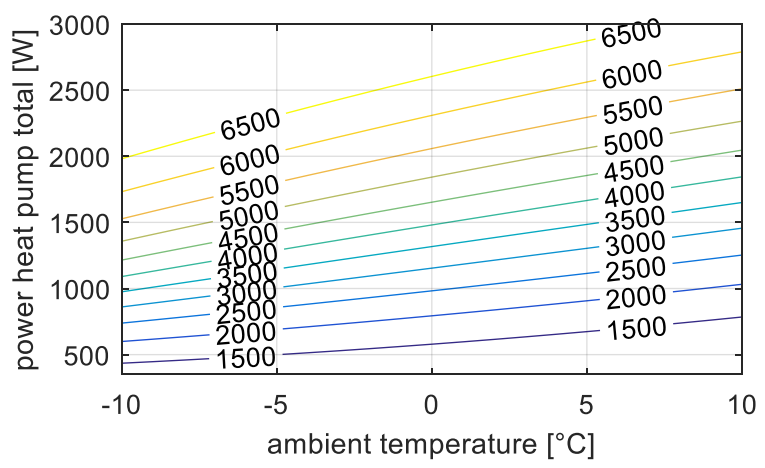

Figure 10: Heating capacity depending on speed of the compressor for supply air $100 \mathrm{~m}^{3} / \mathrm{h}$, secondary air $100 \mathrm{~m}^{3} / \mathrm{h}$, exhaust air $100 \mathrm{~m}^{3} / \mathrm{h}$ and additional ambient air $200 \mathrm{~m}^{3} / \mathrm{h}$.

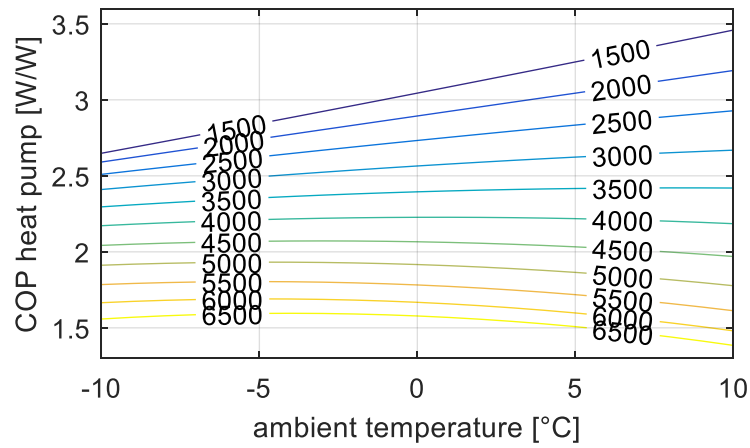

Figure 11: COP depending on speed of the compressor for supply air $100 \mathrm{~m}^{3} / \mathrm{h}$, secondary air $100 \mathrm{~m}^{3} / \mathrm{h}$, exhaust air $100 \mathrm{~m}^{3} / \mathrm{h}$ and additional ambient air $200 \mathrm{~m}^{3} / \mathrm{h}$.

The presented results are used as input data for the simulation. The different steady-state measurement results for possible system states are combined in the simulation work. The transient behaviour of the heat 
pump is considered via transfer functions obtained by the measurements.

\section{Simulation Results and Discussion}

There are two main goals of the simulation study:

- optimize the temperature distribution in the flat compared to a traditional air heating system,

- obtain the overall seasonal system performance.

In this study the goal is to reach in all room $20.5^{\circ} \mathrm{C}$ and to avoid significant overheating or underheating. Underheating leads to dissatisfaction among the residents and overheating to unwished user behaviour, e.g. opening of the windows in the winter. This decreases the overall system performance dramatically. It is very difficult to define fixes values which temperatures represent 'overheating' and 'underheating'. With an operative room temperature of $20.5{ }^{\circ} \mathrm{C}$ and a relative humidity of $50 \%$ a PMV (according to EN 15251) of -0.20 can be determined. This is on the border between category I and II. Assuming the change of one category provides still comfort conditions, for underheating a PMV of -0.50 which represents an operative temperature of around $19.2{ }^{\circ} \mathrm{C}$ is allowed. For overheating a PMV of 0.20 is acceptable which represents an operative temperature of $22.3{ }^{\circ} \mathrm{C}$. Due to comfort reasons the bathroom is in all cases heated to $20.5^{\circ} \mathrm{C}$ with an electrical heater.

Figure 12 shows the temperature distribution for each room in case of a room-wise electrical heater with a PI controller is used. For the visualization a box plot is used. This allows to visualize the frequency and amplitude of the temperature distribution. In all following diagrams only the heating period is used for the analysis.

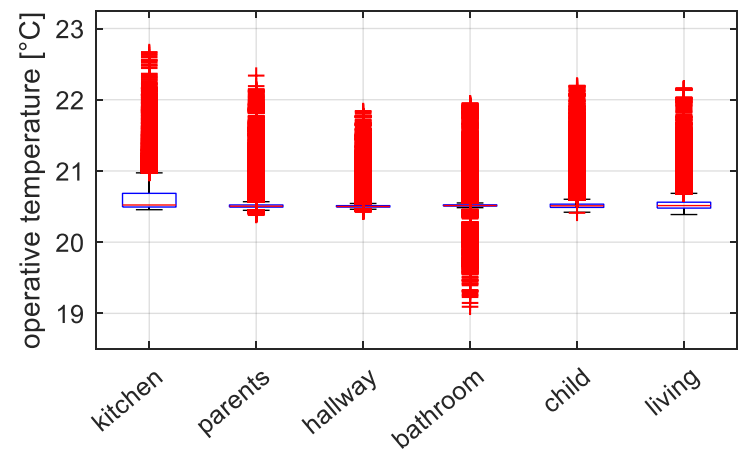

Figure 12: Temperature distribution for electrical heating with PI-controller (climate Innsbruck).

As expected the temperature control works fine. There is no significant over- or undershooting of the temperature. The influence of the solar radiation is due to a relatively high shading factor small (the extreme values with the red markers). In the kitchen the influence of the occupancy profile (cooking) can be obtained clearly. In the bathroom evaporation of water (during the shower) leads also to minor undershoot of the temperature.

Figure 13 shows the temperature distribution with a classical supply air heating system (Figure 6 and Figure 7). High over- and underheating can be obtained in all the rooms. The supply air rooms (especially parents room, but also child room and living room) have a significant amount of overheating hours. Extract air rooms are tending to be underheated but still acceptable according to the definition.

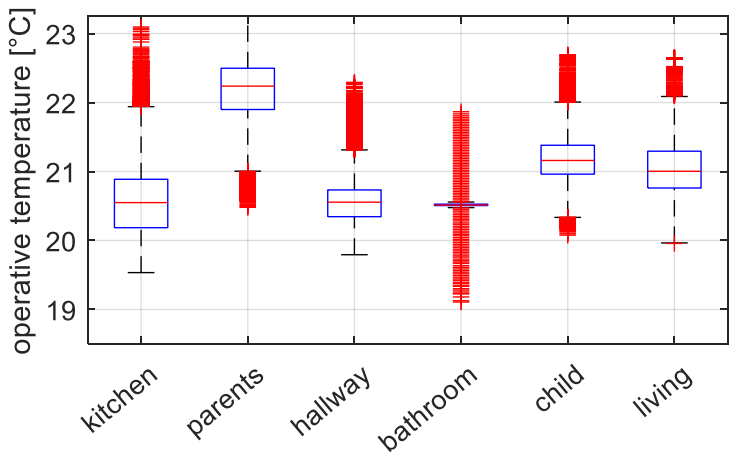

Figure 13: Temperature distribution for supply air $100 \mathrm{~m}^{3} / \mathrm{h}$ (climate Innsbruck).

Figure 14 shows the operating mode with additional secondary air flow (Figure 8 and Figure 9). It is always activated if the heat pump is running.

A significant improvement of the overheating in the parents room can be obtained. Despite this there is still a high variance in the room temperatures during the winter. Around $25 \%$ of the time the temperature is between 19.0 and $20.0^{\circ} \mathrm{C}$. Another $25 \%$ of the time the temperatures are higher than $20.8{ }^{\circ} \mathrm{C}$ and only in around $50 \%$ of the time they are closer to the set point of $20.5^{\circ} \mathrm{C}$.

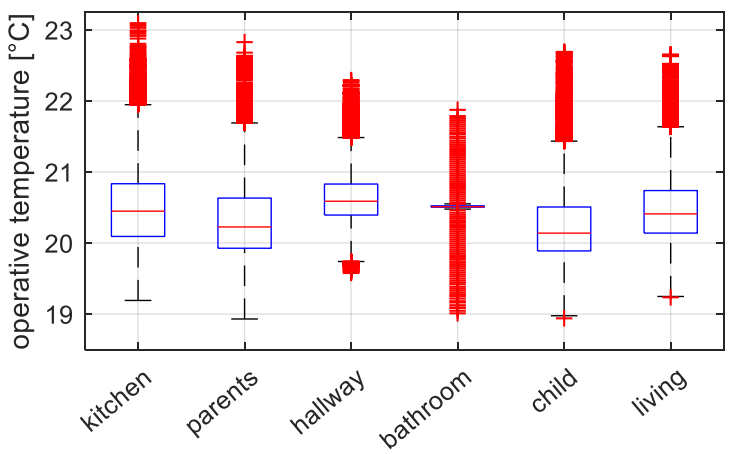

Figure 14: Temperature distribution for supply air $100 \mathrm{~m}^{3} / \mathrm{h}$ and additional secondary air $100 \mathrm{~m}^{3} / \mathrm{h}$ climate (Innsbruck).

Figure 15 shows a further improve of the system. Now the set point of the hallway is set to $21.0^{\circ} \mathrm{C}$. There is an additional electrical heater with a PI controller in all rooms foreseen. The set point is $20.5^{\circ} \mathrm{C}$.

There is no significant underheating observable. In the parents and child room $75 \%$ of the time the temperature is between 20.5 and $21.0^{\circ} \mathrm{C}$. The remaining time the temperatures are less than $21.8^{\circ} \mathrm{C}$.

The different operating modes have also an influence on the efficiency of the heat pump. 


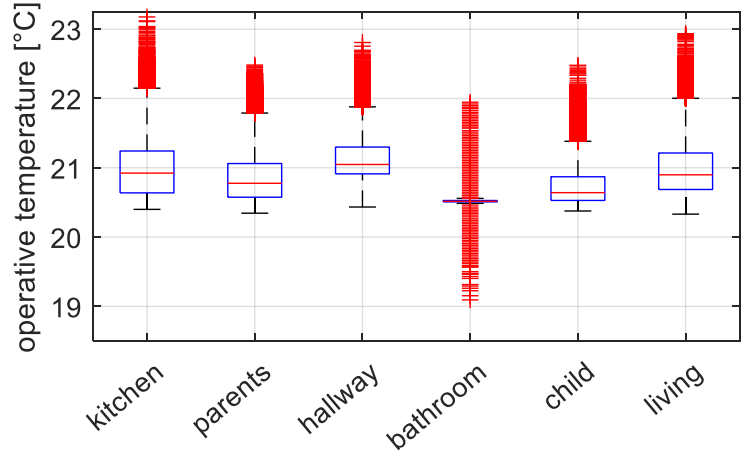

Figure 15: Temperature distribution for supply air $100 \mathrm{~m}^{3} / \mathrm{h}$ and additional secondary air $100 \mathrm{~m}^{3} / \mathrm{h}$ with additional backup-heaters in all rooms (climate Innsbruck).

Figure 16 shows the $S C O P_{H P}$ for the heat pump and the $S C O P_{\text {sys }}$ for the system (according to equation (2) and (4)) for the four presented operating modes.

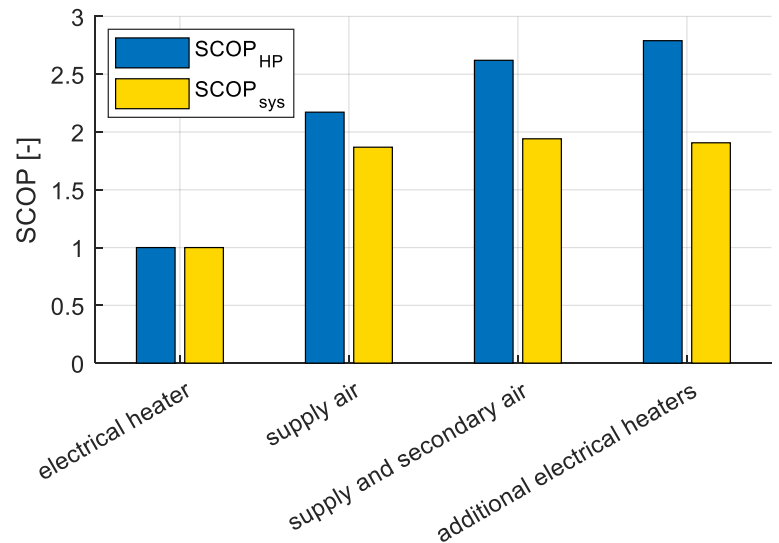

Figure 16: SCOP for the heat pump and the system for the different operating modes (climate Innsbruck).

Figure 17 shows the specific heating demand $Q_{H D}$ for the different operating modes. Due to the over- and underheating in the different operating modes they are not directly comparable. Anyway it is clear to see, that the optimal operation mode in case of an air heating system does not lead to a significant increase in the heating demand.

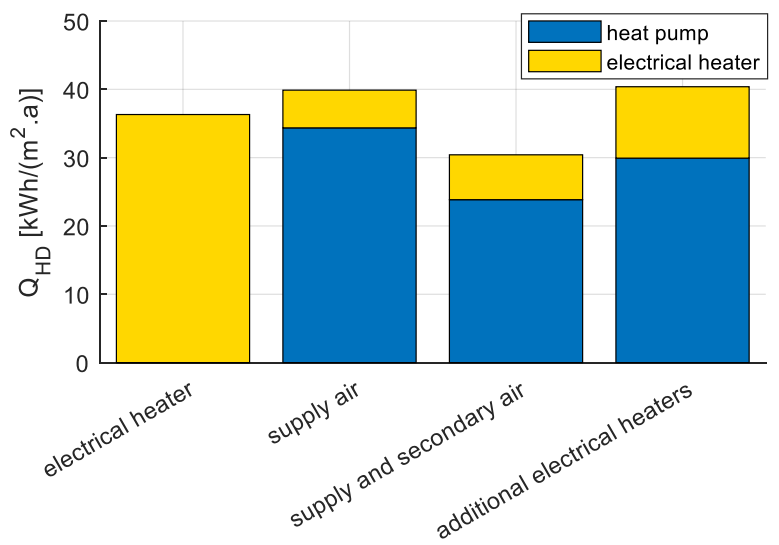

Figure 17: Specific heating demand for the different operating modes (climate Innsbruck).
Figure 18 shows that the electrical energy demand is for the variant with the additional electrical heaters not higher than for a supply air heating system. Moreover the supply air and the "pure" supply and secondary heating have a lower demand due to significant underheating in all rooms in different periods. However, $46 \%$ of the energy demand can be saved compared to room-wise electrical heaters with the same comfort level.

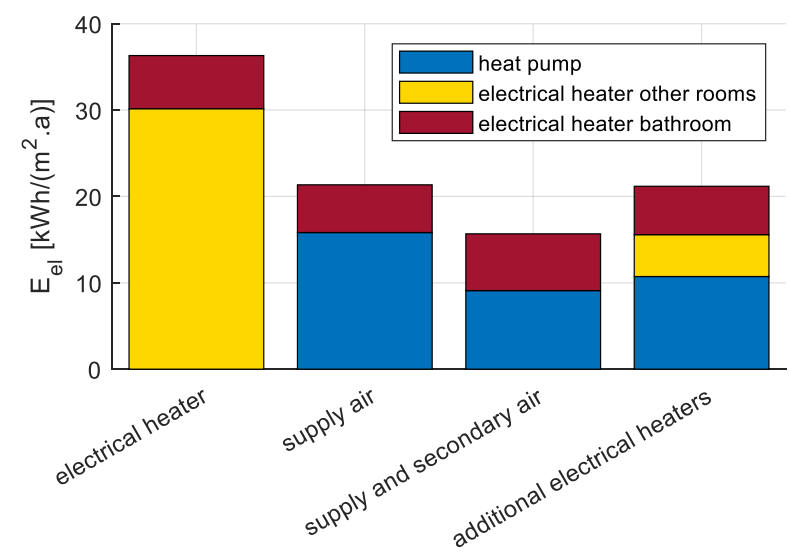

Figure 18: Specific electrical energy demand for the different operating modes (climate Innsbruck).

Figure 19 shows the $S C O P_{H P}$ and Figure 20 the $S C O P_{s y s}$ for the tree different climates. As expected the SCOPs are higher for Lyon than in the Alpine regions. Warth is a village $1500 \mathrm{~m}$ above sea level. There can still be a $S C O P_{H P}$ above 2.0 for the heat pump expected. The $S C O P_{\text {sys }}$ including the room-wise electrical heater is in Warth significantly lower than in Innsbruck or Lyon.

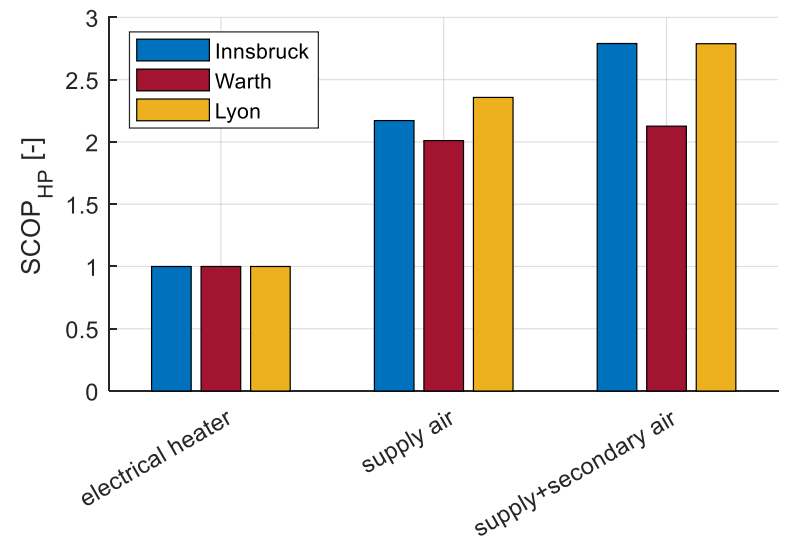

Figure 19: SCOP for the heat pump for the different operating modes and climates. 


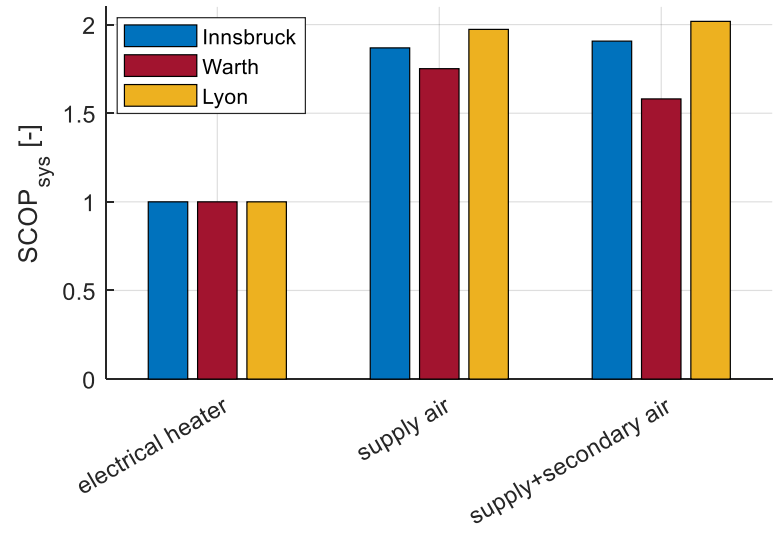

Figure 20: SCOP for the heat pump for the different operating modes and climates.

\section{Conclusion and Outlook}

The ventilation unit combined with a multi-source heat pump is a cost-effective and thus attractive solution for high-energy efficient refurbishment of buildings. Heat power of up to $2.5 \mathrm{~kW}$ with a $S C O P_{H P}$ of more than 2.7 (for Innsbruck and Lyon) can be delivered with the presented solution. Anyhow the system performance $S C O P_{\text {sys }}$ is around 2.0. With a classical air heating system, the heating power is limited to $1.0 \mathrm{~kW}$ in case of only using the hygienical air flow rates. With higher air flow rates higher heating power can be provide but there exists in many climates a high risk of dry air during the winter period. Also a high electrical consumption for the ventilators can be obtained. Moreover this solutions are, compared with the presented one, not suitable for façadeintegration at all.

The largest advantage of the presented solution, compared to a traditional supply air heating system, is the possibility to avoid overheating in the supply air rooms.

Until now the evaluation of the comfort has been done only regarding the operative temperature considering a more or less constant relative humidity during the winter period. An evaluation by using PMW and PPD should still be done.

In further investigations the hardware development of the controller and the test in a Hardware-in-the-loop setup is planned.

Further publications belonging the validation of a heat pump model with measurement data is planned. Also a publication about cooling and de-humidification capability of the presented heat pump is going to be done.

\section{Acknowledgement}

This work is part of the Austrian research project FiTNeS "Fassadenintegrierte modulare Split-Wärmepumpe für
Neubau und Sanierung" (2018-21); Förderprogramm Stadt der Zukunft 5. Ausschreibung 2017, FFG Austria, Project number: 867327.

\section{References}

Ochs, F., Pfluger, R., Dermentzis, G. and Siegele, D. (2017). Energy Efficient Renovation with Decentral Compact Heat Pumps. Proceedings from 12th IEA Heat Pump Conference 2017. Rotterdam (Netherlands), 15-18 May 2017.

Dermentzis, G., Ochs, F., Siegele, D. and Feist, W. (2017). Renovation with an innovative compact heating and ventilation system integrated into the façade - An in-situ monitoring case study. Energy \& Buildings. 165. 451-463.

Mortada, S., Zoughaib, A., Arzano-Daurelle, C. and Clodic, D. (2010). Energy Efficiency of Air-to-Air Mini Heat Pump. Proceedings from 16th International Refrigeration and Air Conditioning Conference 2010. Purdue (USA), 12-15 July 2010.

Ochs, F., Siegele, D. and Jähnig, D. (2018). SaLüH!. Research report. FFG Austria. project number: 850085. 09/2015 - 08/2018.

Siegele, D. and Leonardi, E. (2019). A new MATLAB Simulink Toolbox for Dynamic Building Simulation with B.I.M. and Hardware in the Loop compatibility. Proceedings from Building Simulation 2019. Rome (Italy), 2-4 September 2019.

Siegele, D. and Ochs, F. (2018). Einsatz von Enthalpieübertragern im Mehrgeschosswohnbau in kalten Klimaten. Proceedings from BauSIM 2018. Karlsruhe (Germany), 26-28 September 2018.

Ochs, F., Hauer, M., Bianchi, M. J. and Siegele, D. (2017). Indoor Air Quality, Thermal Comfort and Energy Performance of Membrane Energy Recovery Ventilation in Combination with an Exhaust Air Heat Pump. Proceedings from IBPSA Building Simulation 2017. San Francisco (USA), 7-9 August 2017.

Ochs, F., Siegele, D., Calabrese, T., Dermentzis, G. and Venus, D. (2018). System Simulation Models, Residential Buildings - Part B. IEA SHC TASK 56 Building Integrated Solar Envelope Systems.

Calabrese, T., Ochs, F., Siegele, D. and Dermentzis, G. (2018). Heating with façade integrated heat pumps results of the Austrian FFG project SaLüH!. Proceedings from Advanced Building Skins 2018. Bern (Switzerland), 1-2 October 2018. 